\title{
Oral Lichen Planus in Relation to Transaminase Levels and Hepatitis C Viral Antibodies Detection: A Clinical Study
}

\author{
${ }^{1}$ Geetika Sobti, ${ }^{2} \mathrm{M}$ Manjunath, ${ }^{3}$ TA Deepak, ${ }^{4}$ Sowmya Krishna, ${ }^{5}$ AG Annaji
}

\begin{abstract}
Background: Lichen planus (LP) is a common long term inflammatory disorder that affects skin and mucous membranes. Though mostly asymptomatic in oral mucosa it may cause severe morbidity in erosive cases. The relation between LP and liver diseases especially hepatitis $C$ have been proposed by many authors with varied results. Alteration in liver function tests reflected by increased levels of transaminase levels, i.e., serum glutamic oxaloacetic transaminase (SGOT), serum glutamic pyruvic transaminase (SGPT) with or without the presence of antibodies against hepatitis $\mathrm{C}$ virus (HCV) has been observed in oral lichen planus (OLP) patients in many studies. So this study was undertaken with the intent to further evaluate any alliance between OLP and liver disease principally hepatitis C.
\end{abstract}

Materials and methods: The study consisted of 30 histopathologically confirmed patients of OLP and 30 age and sex matched healthy volunteers visiting the outpatient department of a dental hospital over a period of 1 year. All subjects in both groups were subjected to SGOT, SGPT and HCV antibodies detection.

Results: The percentage of patients with elevated SGOT and SGPT values was higher among the OLP patients in the study group (40\%) in comparison to subjects in the control group (7\%). The mean values of SGOT and SGPT were also higher in the study group in comparison to the control group. No HCV antibodies were found in the serum of subjects in both the study group and control group.

Conclusion: Liver disease or hepatitis $C$ can be considered a risk factor for LP and may lead to diagnosis, early treatment and possibly a better prognosis in asymptomatic OLP patients. Further studies with large samples are recommended to prove the current hypothesis regarding the association between LP and chronic liver disease and/or HCV infection.

Keywords: Hepatitis C virus antibodies, Hepatitis C, Liver disease, Oral lichen planus.

How to cite this article: Sobti G, Manjunath M, Deepak TA, Krishna S, Annaji AG. Oral Lichen Planus in Relation to Transaminase Levels and Hepatitis C Viral Antibodies Detection: A Clinical Study. World J Dent 2016;7(2):64-68.

\footnotetext{
${ }^{1}$ Assistant Professor, ${ }^{2}$ Professor and Head, ${ }^{3}$ Professor,,${ }^{4,5}$ Reader

${ }^{1}$ Department of Oral Medicine and Radiology, RUHS College of Dental Sciences, Jaipur, Rajasthan, India

${ }^{2-5}$ Department of Oral Medicine and Radiology, VS Dental College and Hospital, Bengaluru, Karnataka, India

Corresponding Author: Geetika Sobti, Assistant Professor Department of Oral Medicine and Radiology, RUHS College of Dental Sciences, Jaipur, Rajasthan, India, Phone: +919828082824, e-mail: geetikamohitmidha@gmail.com
}

\section{Source of support: Nil}

Conflict of interest: None

\section{INTRODUCTION}

Lichen planus (LP) is a common, chronic inflammatory immunologically mediated mucocutaneous disease. ${ }^{1}$ It is a disorder of the stratified squamous epithelium that affects oral and genital mucous membranes, skin, nails, and scalp. ${ }^{2}$ Oral lesions are characterized by raised multiform white lesions along with areas of erosion and pigmentation. ${ }^{1}$ The prevalence of LP is unknown, but it is estimated to occur in $<1 \%$ of the population. ${ }^{3}$

The etiology of LP is largely unknown. Its association with human leukocyte antigen (HLA)-BW16, B8, and DRI suggests the possibility of genetic predisposition. ${ }^{4}$

A number of investigators have reported a correlation between LP and certain liver diseases, particularly primary biliary cirrhosis, active chronic hepatitis, and cryptogenic liver cirrhosis, and a common pathogenic basis has been suggested in a number of cases. ${ }^{5}$ The prevalence of this association varies widely in the literature ranging from 0.1 to $35 \%$. Altered liver function tests, i.e., elevated serum glutamic oxaloacetic transaminase (SGOT)/serum glutamic pyruvic transaminase (SGPT), have been detected especially in erosive type of oral lichen planus (OLP). ${ }^{1}$

The possible etiologic role for the cause of chronic liver diseases in relation with LP has been attributed to hepatotropic viruses, especially hepatitis C virus (HCV). ${ }^{6}$ Oral lichen planus has been reported as an extrahepatic lesion induced by HCV. In recent control studies, anti$\mathrm{HCV}$ circulating antibodies were common in patients with LP than in controls. ${ }^{1}$ It is believed that HCV may trigger LP by altering epithelial antigenicity leading to direct activation of cytotoxic $\mathrm{T}$ cells or production of antibodies against epithelial cells. ${ }^{7}$

Considerable discussion has centered in recent years on the relationship between chronic liver disease and LP. Some authors assert the existence of such an association whereas other authors in countries, such as Great Britain have failed to observe any relationship, thus suggesting the existence of some geographical influencing factor. ${ }^{8}$

In view of these conflicting reports and uncertainties regarding the association of $\mathrm{HCV}$ and the liver function status (transaminase levels) in OLP, a need was felt to 
conduct this study and benefit the patients by early detection of any subclinical liver infection.

The aim of this study was to assess the relationship of OLP with elevated transaminase levels and the presence of antibodies against $\mathrm{HCV}$.

\section{MATERIALS AND METHODS}

The study was conducted after obtaining approval by the institutional review board and clearance from the ethical committee. The study was performed on 60 subjects divided into two groups: Study group and control group. Patients were informed about all the procedures to be performed during the study and written consent was obtained. The study group consisted of 30 patients with clinical lesion of OLP selected from the outpatient Department of Oral Medicine and Radiology over a period of 1 year.

Clinically suspected oral lesions of LP were evaluated based on the classification given by Amerikanow (1998), where six clinical forms of OLP were described: ${ }^{9}$

1. Reticular: Consisting of lace-like keratotic lesions.

2. Plaque like: Characterized by homogenous welldemarcated white plaque often surrounded at the periphery by white striae.

3. Papular: Characterized by slightly elevated white pinpoint lesions measuring about 0.5 to $1.0 \mathrm{~mm}$ in size.

4. Atrophic: Combination of erythematous and reticular keratosis.

5. Erosive: Characterized by ulcers with whitish yellow pseudomembrane surrounded by the erythematous zone and fine white radiating striae.

6. Bullous: Manifests as vesicle or bullae surrounded by a reticular network.

In patients with more than one clinical type of lesion, such as reticular and erosive, the most severe form of the disease (i.e., erosive) was used to classify the lesions. All patients in this group were subjected to histopathological examination for confirmation of the lesion. Histological diagnosis was based on the following criteria: ${ }^{10}$

- Hyperortho- or parakeratosis, usually with acanthosis

- Necrosis of the basal cell layer often referred to as "liquefaction degeneration"

- Band of chronic inflammatory cells usually Tlymphocytes in the subjacent connective tissue

In this study the clinical and histological criteria for diagnosis are almost similar to the World Health Organization (WHO) diagnostic criteria (1978) for OLP. Although the latest modified version was also proposed in 2003 by van der Meij and van der Waal, due to complex and notso-clear demarcation in the use of terms like "clinically typical," "clinically compatible with," "histopathologically typical," and "histopathologically compatible with," those criteria were not applied in our study. ${ }^{11}$

Patients with oral lichenoid lesions due to an identifiable cause, such as a hypersensitivity reaction to dental restorative materials or drugs were excluded. Patients suffering from conditions like myocardial infarction, rhabdomyolysis, muscular dystrophy, and dermatomyositis (except liver diseases) were excluded as SGOT and SGPT levels are already altered in these conditions and will not fulfill the objective of the study. These conditions were ruled out by the general physician after detailed medical history, thorough clinical examination, and investigations if required.

The control group consisted of 30 volunteers with age and sex matched with the study group visiting the outpatient Department of Oral Medicine and Radiology for routine dental examination at the same time. The subjects in this group were apparently healthy and were excluded if suffering from conditions like liver diseases, myocardial infarction, rhabdomyolysis, muscular dystrophy, and dermatomyositis (in which the transaminase levels are altered) after referring to the general physician.

All subjects in both groups were subjected to routine blood investigations (such as hemoglobin, complete blood count, and Random blood sugar (RBS)), SGOT, SGPT, and $\mathrm{HCV}$ antibodies detection.

Serum glutamic oxaloacetic transaminase and SGPT were estimated using a commercially available diagnostic kit (Agappe Diagnostics Pvt. Ltd, Ernakulam, Kerala). The normal reference values used for SGOT and SGPT were 8 to $40 \mathrm{IU} / \mathrm{l}$. Values $>40$ were considered positive for both SGOT and SGPT.

Hepatitis $C$ virus antibodies were detected using the commercially available enzyme-linked immunosorbent assay (ELISA) kit, i.e., SP-NANBASE C-96, 3.0. It is an enzyme immunoassay diagnostic kit for in vitro qualitative detection of antibody to HCV in human serum or plasma. Specimens with cut-off value $<1.0$ were considered nonreactive and those t 1.0 were considered reactive.

The $Z$ test was used to compare the mean SGOT and SGPT values in study and control groups, while the chisquare test was used to assess the levels of raised SGOT and SGPT values in the study group and control group. A p-value $\leq 0.05$ was considered statistically significant.

\section{RESULTS}

Gender and age distribution of the 30 patients constituting the study group and 30 subjects in the control group is given in Table 1.

Table 1: Sex and age distribution in the study and control group

\begin{tabular}{llll}
\hline & & $\begin{array}{l}\text { Study group } \\
n=30(\%)\end{array}$ & $\begin{array}{l}\text { Control group } \\
n=30(\%)\end{array}$ \\
\cline { 2 - 4 } & Males & $14(46)$ & $11(37)$ \\
Sex & Females & $16(54)$ & $19(63)$ \\
\hline Age range (years) & $20-67$ & $31-47$ & \\
Average age (years) & 44.27 & 38.57 & \\
\hline
\end{tabular}


Out of 30 patients in the study group, 23 were more than 40 years of age.

While considering the ill-healthy habits like paan/ tobacco chewing, smoking, and alcohol consumption, $10(33.3 \%)$ out of 30 patients reported with at least 1 such habit in the study group. At the same time, there were only $2(13.3 \%)$ subjects with such a history in the control group.

Regarding the site distribution, 28 out of 30 patients in the study group had lesions on buccal mucosa with 6 patients having concomitant tongue lesions and two having exclusive lesions on the gingiva presenting as desquamative gingivitis. Among the 30 OLP patients, a maximum of 16 had a reticular type of LP $(53 \%)$ clinically followed by 8 erosive $(27 \%), 3$ atrophic $(10 \%)$, 2 plaque-like (7\%), and $1(3 \%)$ bullous type; i.e., there were 12 erosive cases and 18 nonerosive cases in the study group

Serum glutamic oxaloacetic transaminase (IU/l) and SGPT (IU/l) levels were altered in 12 cases (40\%) in the study group and only in $2(7 \%)$ out of 30 subjects in the control group.

Moreover, the mean value of SGOT (Table 2) and SGPT (Table 3) was found to be higher in the study group compared to the control group, and the difference in the mean between them was found to be statistically significant $(\mathrm{p}<0.05)$.

Regarding the relation of various clinical forms of OLP with altered liver function tests, out of 12 patients in whom the liver function tests were altered, 6 had erosive type $(50 \%), 3$ had atrophic type $(25 \%), 2$ had reticular type (17\%), and 1 had plaque type ( $8 \%$ ) of OLP. In other perspectives, out of 12 erosive cases, $75 \%$ ( 9 cases) showed elevated SGOT/SGPT levels and out of 18 nonerosive cases 16\% (3 cases) showed altered SGOT/ SGPT levels.

Table 2: Mean SGOT (IU/l) in study and control group

\begin{tabular}{llllll}
\hline Groups & Mean & $\begin{array}{l}\text { Standard deviation } \\
\text { of mean }\end{array}$ & $\begin{array}{l}\text { Standard error } \\
\text { of mealue }\end{array}$ \\
\hline $\begin{array}{l}\text { Study } \\
\text { group }\end{array}$ & 31.05 & 19.92 & 3.64 & -2.560 & $0.010^{*}$ \\
$\begin{array}{l}\text { Control } \\
\text { group }\end{array}$ & 21.43 & 6.06 & 1.11 & & \\
\hline
\end{tabular}

${ }^{*}$ Denotes significant difference, i.e., $p<0.05$

SGOT: Serum glutamic oxaloacetic transaminase

Table 3: Mean SGPT (IU/I) in study and control group

\begin{tabular}{|c|c|c|c|c|c|}
\hline Groups & Mean & $\begin{array}{l}\text { Standard } \\
\text { deviation }\end{array}$ & $\begin{array}{l}\text { Standard } \\
\text { error of mean }\end{array}$ & $Z$ & $p$-value \\
\hline Study group & 37.35 & 28.78 & 5.25 & -2.797 & $0.005^{*}$ \\
\hline Control group & 20.60 & 8.74 & 1.60 & & \\
\hline
\end{tabular}

The mean age of patients with elevated enzyme levels in the study group was higher (45.25 years) than those with normal enzyme levels (27.42 years).

No HCV antibodies were found in the serum of subjects in both the study group and the control group.

\section{DISCUSSION}

The age and sex distribution in our study correlated with the figures mentioned by previous authors. ${ }^{12-16}$ The 4 th to 6th decade of life are the most common age of occurrence with female predominance.

The observation of reticular form being the most common form $(53 \%)$ in our study is similar to the reports in the literature by various authors who have also mentioned it as the most common type occurring in the oral cavity. $2,17-21$

Although LP has a clear immunologic origin, its precise cause remains unclear. In recent years the association between LP and chronic liver diseases has been discussed and a common pathogenic basis has been suggested in a number of cases. ${ }^{5}$

Initially considered as an adverse reaction to penicillamine used to treat primary biliary cirrhosis, LP was later reported to be associated with primary biliary cirrhosis independently of the drug. ${ }^{4}$

The association between LP and hepatitis C is also well documented. Carrazo et al in a study performed in Italy and England observed that there was a higher frequency of HLA class II allele HLA-DR6 in OLP patients with HCV infection in comparison to those without $\mathrm{HCV}$ infection, which also explains the geographical heterogeneity of the association between HCV and LP. ${ }^{22}$

The observation of higher percentage of patients with altered liver function tests as well as higher mean value of SGOT (IU/l) and SGPT (IU/l) in the study group compared to the control group in the present study was in agreement with the results of earlier studies by various authors. ${ }^{1,4,5,23,24}$

The elevation of transaminase levels among the two subjects in the control group can be attributed to the alcohol consumption and other ill-healthy habits affecting the liver.

With respect to the relationship between elevated transaminase levels and the type of OLP, there was 50\% distribution in both erosive and nonerosive groups. But the mean SGOT/SGPT values were higher (70.3 IU/1) in patients with erosive oral lesions compared to those with nonerosive lesions (51.4 IU/1) in the present study, and similar findings have also been reported in the literature. ${ }^{1,5,25}$ This indicates that in the presence of greater liver alterations there is a correspondingly greater tendency toward the development of aggressive oral lesions. 
There are conflicting results about the association of $\mathrm{HCV}$ infection with OLP. Many studies did not find a relationship between the two diseases while others have demonstrated a correlation. ${ }^{25}$

In the present study, all patients in the study group and subjects in the control group who were subjected to the estimation of anti-HCV titer by the highly sensitive ELISA technique were found to be seronegative. Similar finding of no correlation between OLP and HCV infection has also been reported by many other authors. ${ }^{1,25,26}$

The seronegativity found in the present study may be due to the fact that these patients may be either in the initial phase or in the chronic phase of $\mathrm{HCV}$ infection at the time of visit. During the early phase of HCV infection, adequate antibodies are not formed and in the chronic phase antibodies decline in their number, which cannot be easily detected in the serum or the patient may be really seronegative where the transaminase elevation may be caused by factors other than HCV, which might trigger the development of OLP.

But many authors have even reported findings in contrast with the results of our study, suggesting a link between OLP, especially the erosive type, and HCV infection. ${ }^{6,25-29}$

The two main hypotheses discussed by Chainani-Wu et al in their review regarding the mechanism of HCVinduced OLP are that the virus replicate within the oral epithelium and directly contribute in developing OLP lesions. Secondly, HCV has a high rate of mutation, which results in repeated activation of immune cells, increasing the risk of cross-reaction with self-tissue and hence the development of autoimmune diseases. ${ }^{30}$

However, many authors are of the view that host immune response to HCV rather than the virus per se plays a greater role in the development of OLP lesions in HCV-infected patients. As a replicative form of HCV ribonucleic acid can be detected within OLP lesions and an immune-mediated damage of basal layer cells is always present in these patients, evidence for a link between the cell-mediated immune response against $\mathrm{HCV}$ and the pathogenesis of OLP has been reassessed. ${ }^{31,32}$ They have shown HCV-specific T-cell responses at the site of OLP lesions, sustained by terminally differentiated effector cells, strongly suggesting their role in the pathogenesis of tissue damage. ${ }^{32}$

Variation in results highlighting the relationship of OLP with chronic liver disease, especially hepatitis $\mathrm{C}$, may be due to the variation of the incidence of $\mathrm{HCV}$ infection in different geographical areas. This association seems to be strong in Japanese and Mediterranean population probably as they are considered areas of high endemicity for $\mathrm{HCV}$ infection while no association has been found in other areas such as Nepal, Nigeria,
Ankara, Iran, etc. ${ }^{33}$ Hepatitis $C$ virus-related OLP seems to be associated with the HLA class II allele HLA-DR6 in Italian patients but not in British patients, which again partly explains the peculiar geographical heterogeneity of the association. ${ }^{33}$

\section{CONCLUSION}

Thus, it can be inferred that some relation, although controversial, does exist between OLP and chronic liver disease, not necessarily hepatitis $C$; it could be any unidentified type of asymptomatic viral hepatitis. ${ }^{8}$ Lichen planus could be a stereotypic cell-mediated reaction to either a specific virus or several viruses, some of them hepatotropic.

Moreover, as LP can be the first extrahepatic manifestation of HCV infection and because of HCV's significant morbidity and mortality, it is important for the clinician to subject the patients suspected of OLP, especially the erosive form, and those residing in areas where the prevalence of $\mathrm{HCV}$ infection is high to estimation of liver function tests and hepatitis $\mathrm{C}$ antibodies detection to prevent any incidental transmission of HCV to health workers. ${ }^{29,33}$

So, liver disease or hepatitis $\mathrm{C}$ can be considered a risk factor for LP although not a specific marker of it and may lead to diagnosis, early treatment, and possibly a better prognosis in asymptomatic OLP patients. ${ }^{31,33}$ Further studies with large samples are recommended to prove the current hypothesis regarding the association between LP and chronic liver disease and/or HCV infection.

\section{REFERENCES}

1. Ali A, Suresh C. Oral lichen planus in relation to transaminase levels and hepatitis C virus. J Oral Pathol Med 2007 Nov;36(10):604-608.

2. do Canto AM, Müller H, de Freitas RR, da Silva Santos PS. Oral lichen planus (OLP): clinical and complementary diagnosis. An Bras Dermatol 2010 Sep-Oct;85(5):669-675.

3. Carrozzo M, Thorpe R. Oral lichen planus: a review. Minerva Stomatol 2009 Oct;58(10):519-537.

4. GruppoItalianoStudieEpidemiologici in Dermatologia (GISED). Lichen planus and liver diseases: a multicenter case-control study. BMJ 1990 Jan 27;300(6719):227-230.

5. Bagán J, Aguirre J, del Olmo J, Milián A, Peñarrocha M, Rodrigo J, Cardona F. Oral lichen planus and chronic liver disease: a clinical and morphometric study of the oral lesions in relation to transaminase elevation. Oral Surg Oral Med Oral Pathol 1994 Sep;78(3):337-342.

6. Guerreiro TDT, Machado MM, de Freitas THP. Association between lichen planus and hepatitis $C$ virus infection: a prospective study with 66 patients of the dermatology department of the hospital Santa Casa de Misericórdia de São Paulo. An Bras Dermatol 2005 Sep-Oct;80(5):475-480.

7. Ghodsi SZ, Daneshpazhooh M, Shahi M, Nikfarjam A. Lichen planus and hepatitis C: a case-control study. BMC Dermatol 2004 Jun;4(6):6. 
8. Bagán J, Ramón C, González L, Diago M, Milián M, Cors R, Lloria E, Cardona F, Jiménez Y. Preliminary investigation of the association of oral lichen planus and hepatitis C. Oral Surg Oral Med Oral Pathol Oral Radiol Endod 1998 May;85(5):532-536.

9. Petrou-Amerikanou C, Markopoulos A, Belazi M, Karamitsos D, Papanayotou P. Prevalence of oral lichen planus in diabetes mellitus according to the type of diabetes. Oral Dis 2008 Mar;4(1):37-40.

10. DeRossi S, Ciarrocca K. Lichen planus, lichenoid drug reactions, and lichenoidmucositis. Dent Clin North Am 2005 Jan;49(1):77-89.

11. Patil S, Rao R, Sanketh D, Sarode S, Sarode G. A universal diagnostic criteria for oral lichen planus: an exigency! Int J Contemp Dent Med Rev 2014; vol. 2014, Article ID 041214.

12. Huber MA. Oral lichen planus. Quintessence Int 2004 Oct;35(9):731-752.

13. Kövesi G, Bánóczy J. Follow-up studies in oral lichen planus. Int J Oral Surg 1973 Feb;2(1):13-19.

14. Al-Hashimi I, Schifter M, Lockhart P, Wray D, Brennan M, Migliorati C, Axéll T, Bruce AJ, Carpenter W, Eisenberg E. Oral lichen planus and oral lichenoid lesions: diagnostic and therapeutic considerations. Oral Surg Oral Med Oral Pathol Oral Radiol Endod 2007 Mar;103 (Suppl):S25.e1-S25.e12.

15. Carbone M, Arduino P, Carrozzo M, Gandolfo S, Argiolas M, Bertolusso G, Conrotto D, Pentenero M, Broccoletti R. Course of oral lichen planus: a retrospective study of 808 northern Italian patients. Oral Dis 2009 Apr;15(3):235-243.

16. Boyd AS, Neldner KH. Continuing medical education: lichen planus. J Am Acad Dermatol 1991;25:593-619.

17. Scully C, El-Kom M. Lichen planus: review and update on pathogenesis. J Oral Pathol Med 1985 Jul;14(6):431-458.

18. Abbate G, Foscolo A, Gallotti M, Lancella A, Mingo F. Neoplastic transformation of oral lichen: case report and review of the literature. Acta Otorhinolaryngol Ital 2006 Feb;26(1):47-52.

19. Edwards, PC, Kelsch, R. Oral lichen planus: clinical presentation and management. J Can Dent Assoc 2002 Sep;68(8): 494-499.

20. Mollaoglu N. Oral lichen planus: a review. Br J Oral Maxillofac Surg 2000 Aug;38(4):370-377.

21. Rosa L. Oral lichen planus: clinical and histopathological considerations. Rev Bras Otorrinolaringol 2008 MarApr;74(2):284-292.
22. Carrozzo M, Brancatello F, Dametto E, Arduino P, Pentenero M, Rendine S, Porter SR, Lodi G, Scully C, Gandolfo S. Hepatitis $C$ virus-associated oral lichen planus: is the geographical heterogeneity related to HLA-DR6? J Oral Pathol Med 2005 Apr;34(4):204-208.

23. Rongioletti F, Rebora A. Lichen planus and chronic active hepatitis. A retrospective survey. Acta Derm Venereol (Stockh) 1984;64:52-56.

24. Korkij W, Chuang F-Y, Soltani K. Liver abnormalities in patients with lichen planus. A retrospective case-control study. J Am Acad Dermatol 1984 Oct;11(4 Pt1):609-615.

25. Cunha K, Manso A, Cardoso A, Paixão J, Coelho H, Torres S. Prevalence of oral lichen planus in Brazilian patients with HCV infection. Oral Surg Oral Med Oral Pathol Oral Radiol Endod 2005 Sep;100(3):330-333.

26. Campisi G, Di Fede O, Craxı A, Di Stefano R, Margiotta V. Oral lichen planus, hepatitis $C$ virus, and HIV: no association in a cohort study from an area of high hepatitis $C$ virus endemicity. J Am Acad Dermatol 2004 Sep;51(3):364-370.

27. Gandolfo S, Carbone M, Carrozzo M, Gallo V. Oral lichen planus and hepatitis $\mathrm{C}$ virus ( $\mathrm{HCV}$ ) infection: is there a relationship? A report of 10 cases. J Oral Pathol Med 1994 Mar;23(3): 119-122.

28. Chuang T, Stitle L, Brashear R, Lewis C. Hepatitis C virus and lichen planus: a case-control study of 340 patients. J Am Acad Dermatol 1999 Nov;41(5 Pt 1):787-789.

29. Lin L, Lu S, Lu S. Seroprevalence of anti-HCV among patients with oral lichen planus in Southern Taiwan. Oral Surg Oral Med Oral Pathol Oral Radiol Endod 2010 Mar;109(3): 408-414.

30. Chainani-Wu N, Lozada-Nur F, Terrault N. Hepatitis C virus and lichen planus: a review. Oral Surg Oral Med Oral Pathol Oral Radiol Endod 2004 Aug;98(2):171-183.

31. Pilli M, Penna A, Zerbini A, Vescovi P, Manfredi M, Negro F, Carrozzo M, Mori C, Giuberti T, Ferrari C, et al. Oral lichen planus pathogenesis: a role for the HCV-specific cellular immune response. Hepatology 2002 Dec;36(6): 1446-1452.

32. Al Robaee AA, Al Zolibani AA. Oral lichen planus and hepatitis $C$ virus: is there real association. Acta Dermatoven Alp Pannonica Adriat 2006 Mar;15(1):14-19.

33. Scully C, Carrozzo M. Oral mucosal disease: lichen planus. Br J Oral Maxillofac Surg 2008 Jan;46(1):15-21. 